\title{
Challenges and visions for managing pain-related insomnia in primary care using the hybrid CBT approach: a small-scale qualitative interview study with GPs, nurses, and practice managers
}

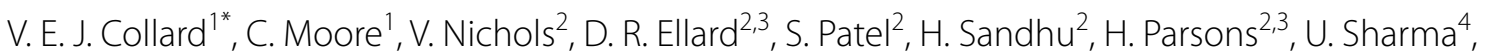
M. Underwood ${ }^{2,3}$, J. Madan $^{2}$ and N. K. Y. Tang ${ }^{1}$

\begin{abstract}
Background: Chronic pain and insomnia have a complex, bidirectional relationship - addressing sleep complaints alongside pain may be key to alleviating patient-reported distress and disability. Healthcare professionals have consistently reported wanting to offer psychologically informed chronic pain management at the primary care level. Research in secondary care has demonstrated good treatment efficacy of hybrid CBT for chronic pain and insomnia. However, primary care is typically the main point of treatment entry, hence may be better situated to offer treatments using a multidisciplinary approach. In this study, primary care service providers' perception of feasibility for tackling pain-related insomnia in primary care was explored.

Methods: The data corpus originates from a feasibility trial exploring hybrid CBT for chronic pain and insomnia delivered in primary care. This formed three in-depth group interviews with primary care staff $(n=9)$ from different primary care centres from the same NHS locale. All interviews were conducted on-site using a semi-structured approach. Verbal data was recorded, transcribed verbatim and analysed using the thematic analysis process.

Results: Eight themes were identified - 1) Discrepant conceptualisations of the chronic pain-insomnia relationship and clinical application, 2) Mismatch between patients' needs and available treatment offerings, 3) Awareness of psychological complexities, 4) Identified treatment gap for pain-related insomnia, 5) Lack of funding and existing infrastructure for new service development, 6) General shortage of psychological services for complex health conditions, 7) Multidisciplinary team provision with pain specialist input, and 8) Accessibility through primary care. These mapped onto four domains - Current understanding and practice, Perceived facilitators, Perceived barriers, Ideal scenarios for a new treatment service - which reflected the focus of our investigation. Taken together these provide key context for understanding challenges faced by health care professionals in considering and developing a new clinical service.
\end{abstract}

\footnotetext{
${ }^{*}$ Correspondence: t.collard@warwick.ac.uk

1 Department of Psychology, University of Warwick, Gibbet Hill Road,

Coventry CV4 7AL, UK

Full list of author information is available at the end of the article
}

(C) The Author(s) 2021. Open Access This article is licensed under a Creative Commons Attribution 4.0 International License, which permits use, sharing, adaptation, distribution and reproduction in any medium or format, as long as you give appropriate credit to the original author(s) and the source, provide a link to the Creative Commons licence, and indicate if changes were made. The images or other third party material in this article are included in the article's Creative Commons licence, unless indicated otherwise in a credit line to the material. If material is not included in the article's Creative Commons licence and your intended use is not permitted by statutory regulation or exceeds the permitted use, you will need to obtain permission directly from the copyright holder. To view a copy of this licence, visit http://creativecommons.org/licenses/by/4.0/. The Creative Commons Public Domain Dedication waiver (http://creativeco mmons.org/publicdomain/zero/1.0/) applies to the data made available in this article, unless otherwise stated in a credit line to the data. 
Conclusions: Primary care service providers from one locale advocate better, multidisciplinary treatment provision for chronic pain and insomnia. Findings suggest that situating this in primary care could be a feasible option, but this requires systemic support and specialist input as well as definitive trials for success.

Keywords: Chronic pain, Insomnia, Sleep, Cognitive behaviour(al)therapy (CBT), Psychological treatment, Hybrid CBT, Patient and public involvement (PPI), Primary care, Thematic analysis, Pain management

\section{Introduction}

In the UK, chronic pain constitutes a substantial burden to primary care in terms of appointment presentation and direct cost. Accounting for 4 million general practitioner (GP) appointments per annum with total healthcare costs approximately double that of individuals presenting without chronic pain [1, 2]. Typically, people with chronic pain present with multiple comorbidities. However, insomnia is consistently cited by patients as the most common and disruptive with up to $90 \%$ reporting symptoms at clinical levels [3-13]. Insomnia alone is a risk factor in the development of many adverse health outcomes, including hypertension, cardiovascular disease, diabetes, respiratory diseases, and increased mortality [14-16]. Poor sleep can be a driver of persistent pain alongside associated distress and disability [17-25].

People with chronic pain have long highlighted better sleep as a key treatment outcome [26-28], but its delivery remains peripheral in pain management programmes (PMPs) even though more than one meta-analyses have now shown beneficial treatment effects of non-pharmacological treatments of insomnia for people with chronic cancer and non-cancer pain $[29,30]$. In primary care, where a considerable amount of day-to-day chronic pain and insomnia management occurs, pharmacological interventions persist as main treatment options, despite limited evidence supporting efficacy and safety beyond 6-12 months [31]. Reported undesirable effects after short-term use include excessive daytime somnolence, increased risks of falls, varied cognitive impairments and road traffic accidents [32-35]; indeed, side effects after long term usage include increased risk of respiratory depression, dementia, and mortality [36-40]. As polypharmacy increases, these effects become more pronounced, especially with combined use of opioids and benzodiazepines which is considered to have contributed to the sharp increase in deaths from accidental prescription drug overdose [41]. Moreover, clinical guidance and review evidence clearly warn about the potential of addiction to insomnia medications, due to the rapid development of tolerance and withdrawal symptoms during dose reduction [42-46] Psychological treatments that simultaneously target chronic pain and insomnia offer promising alternatives [47].
A 2007 evaluation of a talking therapy modified for people with pain-related insomnia presenting at a hospital clinic [10] provided a potential treatment model to adapt into primary care. The intervention simultaneously tackled chronic pain and sleep with select components of CBT-I alongside CBT-P interventions targeting the maintenance processes of chronic pain. This hybrid approach was delivered on an individual basis for 4 weeks via weekly two-hour sessions, the treatment dosage of which approximated the optimal dose recommended for CBT-I $[48,49]$ within stepped care models [50]. Posttreatment, when compared with a symptom-monitoring control procedure, the intervention was associated with greater improvement in sleep. Pain intensity did not change; but hybrid CBT was associated with greater reductions in pain interference, fatigue, and depression relative to the control [10].These findings correspond with those from a handful of other randomised control trials conducted in the USA and Spain with hybrid CBT showing better treatment outcomes, than when CBT-I or CBT-P are offered alone [51-55]. Hence, the addition of CBT-I is necessary for optimal management of pain and pain-related insomnia. Study authors have recently completed a linked feasibility trial to explore how such a service could be delivered in primary care in the UK [56]. This also comprised four weekly, individual 2 hour sessions to reflect optimal treatment dosage for CBT-I and maintain the level of treatment content (1 hour CBT-I, 1 hour CBT-P) whilst minimising travel burdens and treatment durations, of which may hinder engagement in this patient group [56, 57].

Here we report an interview study of primary care staff involved in the feasibility trial, the main aim of which was to inform planning for a future definitive study. However, the content of these discussions spoke to wider issues pertinent for managing pain-related insomnia in primary care. Via thematic analysis [58], we aimed to generate a qualitative understanding of present challenges and possible solutions to providing hybrid CBT and psychological treatment in primary care settings.

\section{Methods}

Recruitment

Participating practices were geographically spread across Coventry and Warwickshire identified by the 
Local Comprehensive Research Network to ensure different demographics, practice settings, and experience with research participation. Practices had between 5000 and 8000 registered patients, with between two and six GPs. Practices' demographic composition was widely varied (respective samples 2.1, 3.7 and $25.8 \%$ in each were of ethnic minority backgrounds). These practices also represented a wide spread of socio-economic backgrounds with respective scores of 8,4 and 1 on the 1-10 Index of Multiple Deprivation (IMD), with lower scores indicating higher levels of deprivation $[59,60]$.

The IMD was used for two reasons; first, to gain a robust sense of relative deprivation of the populations served by our participating practices. Second, as it utilises seven domains known to impact deprivation levels (Income; Employment; Education; Skills and Training; Health and Disability; Crime; Barriers to Housing Services; Living Environment), the resultant data gives a more rounded understanding of potential complexities and barriers (or lack thereof) to a range of questions regarding access to healthcare and relative needs. Previous research has linked indicators of deprivation, such as lower social economic status and other associated factors with poorer sleep and pain outcomes, emphasising the reach of these issues in each of our practice's served populations $[61,62]$.

\section{Sample}

The sample comprises nine primary care service providers (one GP, one nurse, and one practice manager from each participating practice). Three separate group interviews by practice were conducted. One practice manager opted to sit in as an observer of the discussion instead. Participants were purposively recruited via email through the linked feasibility trial. Inclusion of medical, caring and management perspectives was to gain a more thorough understanding of practices' dayto-day operations.

\section{Interviews and procedure}

All group interviews were conducted on-site in each practice, ranging from 30 to $60 \mathrm{~min}$ in duration. Participants were interviewed once post-trial, within 3 months of recruitment completion (May and June 2016, February 2017). A semi-structured interview schedule with 10 seed questions was used to anchor discussion, whilst allowing for organic interactions, i.e., interactions between the interviewer and participants, as well as among participants allow for spontaneity and natural tangents in conversation (Table 1). Digression from the schedule was also allowed, e.g., for the interviewer to follow up on a response with prompts or questions for clarification where appropriate or for the interviewees to discuss related topics. The seed questions were devised during the planning stage of the linked feasibility trial [56] through multiple consensus meetings between research team members to aid with overall process evaluation.

One interviewer conducted each of the group interviews $(\mathrm{VN})$ and made field notes during and immediately after interviews. These did not form part of data analysis but helped keep track of key discussion points and areas for further exploration. Interviews were taperecorded and transcribed verbatim for later analysis (VN, CM, VEJC). VN was a Research Fellow on the study's team with extensive experience in mixed-method methods approaches to health service research and working in the National Health Service (NHS) as an allied healthcare professional. Data transcription was supported by the project co-ordinator $(\mathrm{CM})$ and a psychology PhD researcher affiliated with the study (VEJC), who also observed one of the group interviews. These three researchers did not know the interviewees nor have established links with the practices prior to the study.

The study protocol was reviewed and granted favourable ethical opinion by the Solihull NHS Research Ethics Committee (REC NRES reference number: 14/ WM/1053). Written informed consent was obtained from each participant prior to group interview commencement.

Table 1 Interview seed questions

\begin{tabular}{ll}
\hline 1. & If a patient consults with chronic pain and sleep problems what would be your normal practice? \\
2. & Are there any existing services you may refer people with chronic pain and/or sleep problems to? \\
3. & Do you feel equipped to treat patients with chronic pain and sleep problems? \\
4. & Do you think there are other ways we could be helping these people? \\
5. & If we developed a service for patients with chronic pain and insomnia, what might it look like? \\
6. & Where would it sit as a service primary care/ secondary care or somewhere else? \\
7. & Why did your practice decide to help with this research? \\
8. & Wo you see a need for the treatment we are offering? \\
9. & Would you like to see the service that we are offering continue? \\
10. &
\end{tabular}


Assurances of confidentiality and omissions of potentially identifiable data were made alongside the option for participants to decline any or all the data usage in subsequent analysis.

\section{Data analysis}

Three group interview transcripts formed the data corpus. Thematic analysis was employed, guided by six key processes as set out by Braun and Clarke (2006) [58]. Findings are presented with exemplar quotes that substantiate interpretation. Exemplar quotes were chosen via an iterative process between VEJC, CM, and NT during the latter stages of analysis. The process was then repeated with the wider study team during report production to certify that the chosen quotes best corroborated the thematic narrative. Any quotes which team members felt did not fully reflect or support the narrative were discussed and rectified. All quotes are accompanied by an anonymised practice identifier, such that the extent to which each practice is represented in the results is transparent.

Two researchers (CM and VEJC) performed the analysis independently using NVivo, as a means to further establish rigour and credibility, and allow for unanticipated independent insights [63, 64]. Initial codes and themes were discussed between them to resolve any differences in opinion. The agreed codes and themes were then discussed and re-organised with senior team members, who served as content-experts to contextualise generated themes in relation to previous research and clinical practice experience (DE, VN \& NT). Themes were derived from the data within parameters discussed in the interview schedule. Themes that 'survived' this stage of analysis were then sent to all group interview participants for comments, as a further step to enhance credibility and authenticity of the analysis [63]. As an additional measure for credibility, follow-up meetings (conducted November 2018) with NT and VEJC were offered to all three practices as an opportunity to discuss and review initial findings. Two face-to-face meetings took place, each was approximately one-hour long. One practice could not commit to a follow-up meeting due to key personnel change and heavy workloads, however, did provide email confirmation that they were satisfied with initial analysis and direction.

\section{Results}

In total, eight themes were identified, which mapped onto four broad domains drawn out from the interview schedule. Themes and domains together contextually presented the issues of concern and were seen as functionally linked whereby the dynamics of perceived facilitators and barriers inform whether current practice can evolve into ideal treatment scenarios (Fig. 1).

\section{Current understanding and practice \\ Discrepant conceptualisations of the chronic pain-insomnia relationship and clinical application}

An important thread running through all discussions was how participants understood the chronic pain-insomnia relationship and subsequent implications to treatment. There were nuanced differences between GPs in terms of

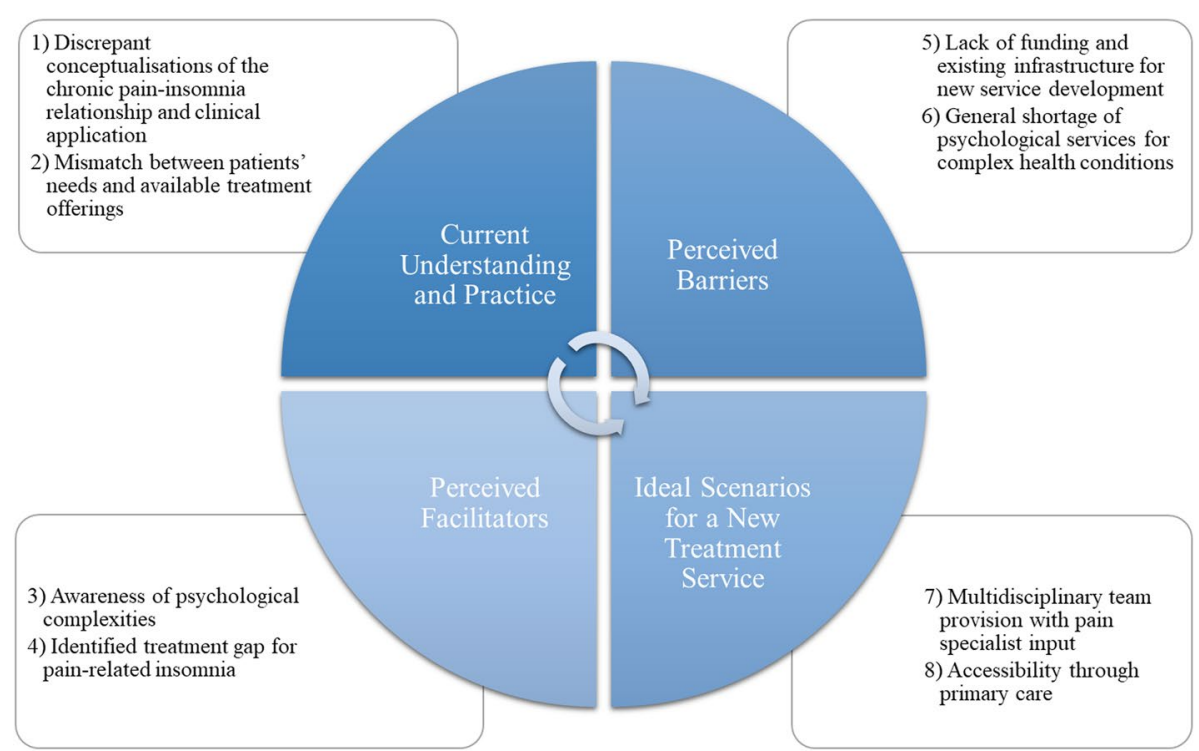

Fig. 1 Summary of eight extracted themes mapped onto four domains embedded in interview structure 
understanding and treating patients presenting with pain and pain-related insomnia. Such that, whilst some providers considered pain-related insomnia as a symptom of chronic pain, others showed appreciation that its presentation could have a reciprocal impact on pain and would prescribe or prioritise treatment accordingly.

A) Practice A: "Well to try and sort out what's the cause of the chronic pain and try to alleviate that and see if that improves their sleep problems... Undoubtedly pain affects sleep long term [...] pain will affect sleep over a long period of time.....

B) Practice B: "So if I had a patient who had insomnia symptoms as well I would strive to treat the insomnia as well as the pain because what you find is insomnia can exacerbate the pain and the pain can exacerbate the insomnia. So for us it's dual approach in treatment."

These variations in views or working hypotheses ultimately fed into differences in prescription and treatment plans specific to sleep. Some showed high confidence of certain drugs' effectiveness in aiding sleep whilst others showed reluctance in using hypnotics the primary intervention for managing insomnia. It is often the case that hypnotics are the first and only intervention proposed however, as per clinical recommendations, should not be the primary intervention for people presenting with sleep disturbances [65]. These differences were embedded within our sample's different treatment heuristics and practice policies.

C) Practice B: "The sort of chronic neuropathic pain drugs especially Amitriptyline is the favoured one which we use a lot in terms of trying to ensure patients get quality sleep but also trying to manage the pain...."

D) Practice C: "As for us prescribing anything for the sleep which is discouraged in our practice. We don't start anyone on any form of hypnotics or sleeping tablets in this practice".

The surge in research and clinical interest regarding sleep and pain's bi-directional relationship has only recently occurred $[66,67]$. Thus, evidence demonstrating a stronger influence from sleep disturbances on pain than from pain to sleep and therapeutic effects of insomnia treatment for pain management and quality of life may not have fully translated to clinical practice yet. Interestingly, participation in research was cited as a practical way to mitigate this.

E) Practice C: “...sometimes you want to review your practice and see what other people are doing and where different people or different health professionals are coming from. That gives their perspective too and also when there is... when you get to know the results of the study then... you try to change your practice."

\section{Mismatch between patients' needs and available treatment offerings}

Discussions show that medical staff's treatment decisions were strongly motivated by the idea of targeting an "underlying" cause.

F) Practice B: "When the patient presents with insomnia as their overriding issue then clearly we try to identify the underlying cause of what that might be. It could be due to a chronic back problem it could be down to a rheumatological issue..."

Initially using a unimodal treatment approach to deal with comorbid chronic conditions like pain and painrelated insomnia that share a bi-directional relationship and a biopsychosocial underpinning $[68,69]$, give way to at least two inherent dilemmas. First, initial applications of 'underlying cause first' treatment logic would restrict the treatment focus to the pain. This might impede treatment progress as chronic pain is, by definition, intractable and patient's quality of life is typically determined by more than just pain severity. Second, for cases that were thought to have a strong 'social' or 'psychological' element, medical staff felt they would ultimately struggle to offer what the patient actually needed considering that the treatment options at their disposal were mainly pharmacological in nature.

G) Practice C: "I often feel patients are caught in a system now whereby sometimes all the issues aren't addressed because a big part of pain is psychological. And I feel the psychological element of pain is never investigated...We don't have like a pain service, purely psychological services. We have the chronic pain service which meets the pain issue with ....medication or with injections...We have got the [Improving Access to Psychological Therapies] IAPT service...But I don't think they're so geared up to treating painrelated psychological issues they may be more geared up towards the depression..."

H) Practice C: “... People with chronic pain for example are living in flats where there are no lifts or their housing problems or transportation ...These are certain small things which may not affect general population but may affect these small cohort of patients more..." 


\section{Perceived facilitators}

Awareness of psychological complexities

Overall, there is some shared understanding that pain is a multidimensional, individuated experience and that this should be reflected in treatment provision. Hence, participants welcomed the idea of a new service to simultaneously manage chronic pain and insomnia. Particularly, that the psychological elements accompanying chronic, complex health conditions should form part of treatment guidance. From our sample, it seems that practices are keen to shift towards a more integrated, biopsychosocial formulation supporting selfmanagement in chronic pain and pain-related insomnia in primary care.

I) Practice A: “...within primary care...there is a very big move away from using medicines to treat insomnia...I don't necessarily think drugs are always the answer because drugs tend to cover symptoms up, particularly with pain. And drugs have lots and lots of side effects too, so I like the idea of something which is non-drug related ideally it should also empower the patient to take their share of responsibility for what is a long-term condition..."

\section{Identified treatment gap for pain-related insomnia}

Enthusiasm for a new psychologically informed service for pain-related insomnia provided under one roof, in part, stemmed from a clear treatment gap, where staff saw an ever-increasing demand in their practice populations and a general absence of long-term meaningful psychological support for this patient group.

J) Practice A: "I think it's a big population group [people with both pain and insomnia]. And I think we've probably got tens of patients who'd benefit from it. There are 36 practices...so you're probably looking at hundreds of patients every year who'd need something like this. So it's a big thing."

However, discussions showed disparity between this awareness and the reality of what primary care staff could feasibly offer to patients. This fed into current management of these issues was considered a major burden to GP time, hence, costly.

K) Practice C: “There's not an awful lot of services for them really...If I saw somebody having chronic pain that was sleep-related, I wouldn't know what to do."

L) Practice B: “... if we had a pain management service in house, I could probably reduce my consultations by probably $20 \%$."
Participants expressed that if the new treatment could help patients improve their quality of life, return to work, and reduce long-term utilisation of health services, demonstrating the resultant financial savings could be a key motivator of service development.

M) Practice A: "Look at returning people to work... The longer people are off work the less chance they've got of going back...could be very cost-effective to invest in these people."

\section{Perceived barriers \\ Lack of funding and existing infrastructure for new service development}

Funding, location, and delivery seemed to be the most prominent issues associated with new service development. Although these barriers are not specific to the proposed new pain-related insomnia service development; their inclusion is necessary to corroborate similar barriers to treatment provision in other long-term, complex health conditions. Indicative of the economic climate at time of data collection, a major concern was if there was enough funding available to design and implement a new service. Participants highlighted that commissioning decisions were based on not just patient benefits but also financial savings, as money was ring-fenced for priority areas to fund services considered by NHS Clinical Commissioning Groups (CCGs) as 'absolutely required'. Thus, the amount of money left to commission new services was considered relatively limited.

N) Practice A: “...you've got a devil's own job being able to demonstrate that, because at the moment in the NHS being able to demonstrate benefit doesn't seem to be enough, you have to demonstrate financial savings."

O) Practice B: “...the difficulty is as far as the CCG's position is concerned is [they're] in a financially compromised position. They're addressing services that they feel are absolutely required."

Although patient demand is there, there is no established care pathway for accessing psychological treatments for chronic pain, even less so for pain-related insomnia. Considerations were given to how the proposed Hybrid CBT could be offered in primary or secondary care, to maximise treatment coherency and patient uptake. Each practice focussed on specific issues surrounding lack of general infrastructure, which may echo what they see as most troublesome for their patients. 


\section{General shortage of psychological services for complex health conditions.}

Participants were aware of the fact that medical staff would not have the time and training to deliver the proposed new service, thus expressed concerns over a shortage of psychologists sufficiently trained to deal with patients who present with complex health conditions in existing primary and secondary care services.

P) Practice A: "We haven't really got access to anybody who's specifically good with insomnia. ... we use IAPT for low level psychology problems that may be the kind of place you could refer somebody for insomnia, maybe. I don't think anybody's pulled the two things [chronic pain and insomnia] together...."

Certainly, there is awareness of current psychologically informed services dealing with insomnia, but not at the level of complexity required for pain-related insomnia. Moreover, potentially symptomatic of how pain and its comorbidities are dealt with, it does seem that even where there is psychological provision this is either a last resort or peripheral in current treatment plans.

Q) Practice B: “... [the pain clinic] say there's a psychotherapist or psychologist already working there, which I don't think is being utilised really to its full effect or they're being inundated..."

\section{Ideal scenarios for a new treatment service}

\section{Multidisciplinary team provision with pain specialist input}

Regarding future treatment, all participants showed conviction in how they thought this should manifest to address patients' needs. Whilst the treatment adopted in the current feasibility trial was offered as a stand-alone psychological intervention, there were strong feelings that future developments of such treatment should look at provision by a multidisciplinary team.

R) Practice A: “...it would be a multidisciplinary service, it would probably have physiotherapists...osteopaths and chiropractors involved...I think also in there, I don't know whether it needs a psychologist or whether it needs just counsellors but it needs somebody in there to look at the psychological aspects of the pain, its effect on insomnia and strategies that that person can use when its three o'clock in the morning....and they haven't got any sleeping tablets or pain killers."

Such that the nature of the service would be coordinated, with psychological and practical support for patients and an emphasis on promoting self-management.
S) Practice C: "It has to be a multi-disciplinary approach with different health professionals specialising in different avenues for managing these patients, sit together and formulate a management plan."

There was, however, less certainty with regards to where the new service should sit within existing treatment pathways. Discussed options included incorporating the service into current PMPs, IAPT services, and setting up a separate service specifically for pain and sleep management to be supported and shared by a collaborative GP network.

T) Practice B: "You could align it with IAPT if you wish. But you'd need someone who has a specialist interest and understands pain in the essence..."

\section{Accessibility through primary care}

Regardless of where the service might sit within existing care pathways, one key requirement for such new treatment service was accessibility. This, combined with previous suggestions that the service should bolt on to the pain clinic's multi-disciplinary team, brought forth debate as to whether the service would situate better within primary or secondary care from both conceptual and practice perspectives.

U) Practice C: “...The first port of call for any patient is primary care...with the current economic climate if at all we set up a service which is going to affect the secondary care or hospitals more then I don't think it will be a good use of NHS resources, so it has to be primary care."

V) Practice B: "Best centred here [primary care]. Because the demand is here.....and based in practice...being local... A lot of them rely on buses and things like that. A lot, sorry quite a fair few don't drive, especially the elderly patients... and financially, they've got to pay out to travel in as well."

Even though differences exist between discussions, overall, a change in situation and access points from largely secondary to primary care level was considered necessary for optimal delivery and accessibility.

W) Practice A: "It's the kind of problem that should be sourceable in primary care but administratively I'm not sure how you would do that in each individual practice. So you probably need some kind of hub..."

Indeed, trade-offs in terms of practicality and current financial constraints were felt to impede creating new, or even altering current treatment pathways for pain-related insomnia patients. 


\section{Discussion}

We have identified primary care viewpoints from three practises in a single NHS locale on care provision for patients with pain-related insomnia, from their experiences as trial sites for a recent feasibility study [56]. Guided by a semi-structured interview schedule, our participants considered the current landscape of tackling pain-related insomnia in primary care and how it might be improved within the current parameters as well as ideal scenarios. Their viewpoints were contextualised through eight themes, situated within four broad domains that reflect the focus of investigation (Fig. 1). The overall sum of discussions speaks to a need for an integrated service supported by an established yet adaptive infrastructure in the care system. This coincides with the hybrid treatment concept $[56,57,70]$ that surrounds the data corpus and recommended strategies on how this could be successfully implemented. Our subsequent discussion points are framed as starting points for future trials, taking into account that much of the components and questions for successful management are in flux.

\section{Is the proposed integrated service worth the challenges, and are these unique?}

Implementing an integrated service in primary care will incur some challenges, namely that the appropriate infrastructure, is not yet in place to deliver such treatment for this patient group [39, 71]. Infrastructure is manifold in describing the sum of physical, technical and organisational components needed in the context of healthcare delivery [72]. This involves complex, highly integrated areas such as staff structure and training, framework situation and physical location, and treatment pathways/access points [73] when considering developing existing or new services. This is inclusive of a lack of a fully empirically validated protocol specific to pain patients presenting with pain-related insomnia [70] as well as a shortage of trained therapists to ensure appropriate delivery and follow-up [48, 50]. A previous qualitative systematic review synthesised these issues in relation to differing beliefs and expectations of both patients and GPs [74]. Specifically, in the context of beliefs about pain, treatment expectations, trust, and patient education. Findings also advocate a shift away from specialist services to treat pain in intensive, short time periods to community services that would provide ongoing holistic patient assistance including managing comorbidities [75]. However, there are numerous common barriers that contribute to this evidence-practice gap, inclusive of primary care staff's misconceptions of addressing and implementing recommended treatment guidelines for best practice [76].
Arguably, these issues around infrastructure and implementation of best practice are not new nor specific to the management of pain-related insomnia. Given that comorbidity in chronic conditions and simultaneous presentation tends to worsen prognoses, intervention and management at the primary care level may lessen some of these associated challenges [77]. This may address previously stated undesirable outcomes associated with current pharmacological provision as 'go-to' treatment options for both chronic pain and insomnia management [29-38]. Moreover, there is some evidence demonstrating cost-effectiveness from successful collaborative care models in depression to promote biopsychosocial care models in primary care for chronic pain and insomnia [78]. Further integration and education of psychological care and PMPs in practices could also meet patients' described needs and boost clinical adherence $[74,76]$.

\section{Is CPD a solution to address discrepancies in clinical practice?}

Linked to infrastructure issues is information discrepancy surrounding how the pain-sleep relationship is conceptualised. This was reflected in differences between practices regarding how pain-related insomnia was described and treated whilst utilising secondary management models [79]. This may stem from clinical education around pain during medical training and post-qualification. Pain education is fragmented, falling short of what might be expected given the prevalence and burden of chronic pain across Europe [5]. Of 28 UK medical schools surveyed, only 11 had a dedicated pain medicine module, of which 4 offered it as a compulsory element [80]. None of which indicated addressing pain-related insomnia. However, evaluative research with the same dataset identified potential facilitators including reframing clinical management using a biopsychosocial framework [81]. Such was reflected in our participants' considerations for improvements and ideal treatment scenarios. Since research has demonstrated the existence of a complex, bi-directional relationship which informs pain-related insomnia [17, 18, 20, 21, 25, 66, 82-84] further education and information exposure should focus on its clinical application and treatment in line with recommendations of integrated, multidisciplinary service provisions [85].

\section{Should a new service situate in primary or secondary care?}

Even with differences between our participants about where such a service should situate in a treatment framework, there was clear support regarding psychological input and allied health professionals to run and manage it. Previous evaluation of nurse administered CBT-I for persistent pain has shown promising results through 
using relevant professionals to conduct effective delivery and specialist training of other relevant staff [86] as have other self-management programs for other chronic conditions such as arthritis, diabetes and asthma [87]. This would certainly fit with pain management recommendations advocating multidisciplinary, biopsychosocial approaches to chronic pain and insomnia management $[88,89]$. However, according to the most recent National Pain Audit [90] there is an overall lack of multidisciplinary provision, even though $64 \%$ of NHS England services describe themselves as such, only $40 \%$ meet criteria (inclusion of a psychologist, physiotherapist and physician). Moreover, the Midlands (our practices' geographical situation) are relatively poorly served with the least access to such provisions. Guidance on future planning of pain management service strongly encourage psychologically informed, multidisciplinary treatment of chronic pain to be available at the primary care level [91]. Thus, mirroring views expressed by our participants and policy guidance could be the basis for productive discussion on how to further research such provision in primary care.

\section{New service development or augment existing pathways?}

By boosting psychological support in primary care through multidisciplinary avenues, there is potential to make sure that service provision is not solely GP dependent $[1,92,93]$ and meet this patient group's treatment expectations [94]. Interestingly, the clinical and cost effectiveness of sleep management in pan management programmes has been noted as a key issue to be addressed in future research as per the 2020 NICE draft guidelines [95]. Another option may be to augment treatment pathways and redistribute resources in PMPs or IAPT to meet described needs and provide a more cohesive, integrated service [96]. However, participants highlighted concerns that in their current forms these services are not adequately resourced to deal with the complex needs of pain-related insomnia. Indeed, there is review evidence that implementing clinical networks can improve overall healthcare delivery for complex conditions, thus bring together some currently disparate treatment avenues and build rationale for more specialist interventions to slot into some currently available services [96]. However, these issues warrant more definitive discussion between researchers, practitioners, and CCGs in the design of future trials or service development [91].

Recently, there has been some considerable progress made in terms of prescribing and delivering psychological interventions for insomnia using digital platforms. CBT-I is a manualised psychological intervention with a rich evidence base, as such is well placed as a scalable solution to bridge gaps in feasible delivery and access for people presenting with sleep complaints [97]. After rigorous testing and evaluation "Somryst" (previously known as Shut-i) has been given Food and Drug Administration (FDA) approval in the USA as a prescribed treatment for insomnia [98]. Similarly, in a UK/NHS context "Sleepio" has accrued an extensive evidence base supporting its acceptability, feasibility, and efficacy across a range of populations presenting with sleep complaints [97, 99-102]. Interestingly, there is a trial protocol to explore the efficacy of "Sleepio" for people with lower back pain which could prove fruitful and leverage the case made for addressing sleep complaints as a core component of PMPs [103]. Given the success of using digital platforms to disseminate CBT-I, it is possible that providing CBT-P and hybrid CBT through digital platforms could follow similar trajectories. The potential utility and cost-effectiveness of prescribing and delivering hybrid CBT using online platforms could help mitigate some of our participants' mentioned barriers to treatment access. Central to these are related to an observed lack of trained therapists trained to understand and deal with the oftencomplex presentation of pain-related insomnia, as well as barriers to travel for older people, those on fixed incomes, frail, or with caring responsibilities.

\section{Limitations}

As the purpose of these interviews was to inform the perceived feasibility of setting up a Hybrid CBT for pain and insomnia RCT [56], gaining insight from managerial, allied, and medical perspectives was deemed suitable. It is however acknowledged that there were possible demand characteristics on our clinical partners that might bias their views. Whilst there is no way to formally assess this, taking account of this possibility is important in the overall interpretation of these findings. Our sample size was small but in line with what was practically possible for a small-scale feasibility study [56]. The principle of 'information power over data saturation' has been applied here [104], whereby aim, specificity, theory, dialogue, and analysis are used to reflexively decide appropriate sample size [104, 105]. Information power suggests that the more information a given sample holds relevant to the study, then a lower number of participants is needed to develop new knowledge. Data saturation, in contrast is a process of constant comparison where every new observation is compared with previous analysis until no new information can be gained [106].

Differences in current practice between our practices may reflect differences in the operational characteristics as they were purposively sampled for the linked feasibility trial to consider geographical location, register size and population served, and experience in research participation. However, it is unclear exactly how these operational characteristics are shaping these practices' differences in terms of chronic pain and insomnia treatments and 
would be an interesting focus for further research. Appropriate measures were taken to ensure rigour and transparency. Moreover, the interview schedule did not allow the examination of how GPs treat individual case presentations of chronic pain and/or pain-related insomnia. Thus, we could not delve into the nuances of current practice at the individual level. As a final point, because discussion was based on general recollection, there is always the possibility that these may not be wholly accurate representations of current practice.

\section{Conclusions}

Tackling pain-related insomnia in primary care is a hugely complex issue where many components are in flux. This study provides some frontline experience about the current and future perceived landscape of treating pain-related insomnia in the context of primary care. These findings are consistent with other research and policy outlining the need to consider providing integrated, multidisciplinary care at the primary care level, with specialist input from relevant professionals, every step of the way, especially in the early stages of development $[90,95]$. Moreover, the development of future trials and subsequent rolling out of tested interventions require systematic support with an existence of appropriate infrastructure. Although not definitive, these findings do offer possible directions for future research, clinical practice, and people-centred service development.

\section{Abbreviations}

PMPs: Pain management programmes; CBT: Cognitive behavioural therapy; CBT-I: Cognitive behavioural therapy for insomnia; CBT-P: Cognitive behavioural therapy for pain; GP: General practitioner; NHS: National Health Service; CCG: NHS clinical commissioning groups; IAPT: Improving Access to Psychological Therapies; FDA: Food and Drug Administration.

\section{Supplementary Information}

The online version contains supplementary material available at https://doi. org/10.1186/s12875-021-01552-3.

\section{Additional file 1.}

\section{Acknowledgements}

The author(s) wish to thank the NHS primary care staff who took the time to be interviewed and discuss some our initial findings with us.

\section{Disclaimer}

The views expressed are those of the author(s) and not necessarily those of the NHS, the NIHR or the department of Health and Social Care.

\section{Authors' contributions}

All authors have contributed to the interpretation of the data and manuscript preparation. NKYT was the principal investigator on the project. NKYT, HP, HKS, SP, DRE, JM, US and MU were involved in the initial design of the study in which the data corpus for this article is situated. VN conducted the interviews with primary care staff with assistance from VEJC. CM and VEJC conducted the data analysis with expert input from VN, DRE and NKYT during its formative stages. All authors reviewed the manuscript prior to submission. The authors read and approved the final manuscript.

Funding

This paper presents independent research funded by the NIHR under its Research for Patient Benefit (RfPB) Programme (Grant Reference Number PB-PG-0213-30121)

\section{Availability of data and materials}

The dataset generated and analysed during the current study are not publicly available due to potentially identifiable information given by participants but is available from one of the senior authors (Prof Nicole Tang; n.tang@warwick. ac.uk) on reasonable request.

\section{Declarations}

\section{Ethics approval and consent to participate}

Our study protocol was reviewed and granted favourable ethical opinion and approval by the Solihull NHS Research Ethics Committee (REC NRES reference number: 14/WM/1053). As such, all data collection and subsequent analysis methods were carried out in accordance with relevant guidelines and regulations. Written informed consent was obtained from each participant prior to group interview commencement. Assurances of confidentiality and omissions of potentially identifiable data were made alongside the option for participants to decline any or all the data usage in subsequent analysis.

\section{Consent for publication}

Written informed consent was obtained from each participant prior to group interview commencement. Assurances of confidentiality and omissions of potentially identifiable data were made alongside the option for participants to decline any or all the data usage in subsequent analysis and publication.

\section{Competing interests}

HS \& SP are directors of Health Psychology Services Ltd. which in part provides psychological treatments for those with chronic pain. HS and HP are chief investigators and co-investigators on other NIHR funded projects relating to chronic pain. MU is chief investigator or co-investigator on multiple previous and current research grants from the UK National Institute for Health Research, Arthritis Research UK and is a co-investigator on grants funded by the Australian NHMRC. He is an NIHR Senior Investigator. He has received travel expenses for speaking at conferences from the professional organisations hosting those conferences. He is a director and shareholder of Clinvivo Ltd. which provides electronic data collection for health services research. He is part of an academic partnership with Serco Ltd. related to return-to-work initiatives. He and $\mathrm{HP}$ are co-investigators on a study receiving support in kind from Stryker Ltd. He has accepted honoraria for teaching/lecturing from the Confederation for Advance Research Training in Africa. He was until 2019 an editor of the NIHR journal series, and a member of the NIHR Journal Editors Group, for which he received a fee. NKYT received grant funding as co-investigator from NIHR for other projects and current funding from the Medical Research Council as principal investigator. NKYT is also a member of the trial steering committee of an ongoing trial of insomnia treatment in primary care funded by the NIHR. There are no competing interests to be reported by any of the other authors.

\section{Author details}

${ }^{1}$ Department of Psychology, University of Warwick, Gibbet Hill Road, Coventry CV4 7AL, UK. ${ }^{2}$ Clinical Trials Unit, Warwick Medical School, University of Warwick, Coventry CV4 7AL, UK. ${ }^{3}$ University Hospitals Coventry and Warwickshire NHS Trust, Coventry CV2 2DX, UK. ${ }^{4}$ University/User Teaching and Research Action Partnership, University of Warwick, Coventry CV4 7AL, UK.

Received: 15 April 2021 Accepted: 1 September 2021 Published online: 20 October 2021

References

1. Belsey J. Primary care workload in the management of chronic pain A retrospective cohort study using a GP database to identify resource implications for UK primary care. J Med Econ. 2002;5(1-4):39-50. 
2. Hong J, Reed C, Novick D, Happich M. Costs associated with treatment of chronic low back pain: an analysis of the UK general practice research database. Spine. 2013;38(1):75-82.

3. Ohayon MM. Relationship between chronic painful physical condition and insomnia. J Psychiatr Res. 2005;39(2):151-9.

4. Bigatti SM, Hernandez AM, Cronan TA, Rand KL. Sleep disturbances in fibromyalgia syndrome: relationship to pain and depression. Arthritis Care Res. 2008;59(7):961-7.

5. Breivik H, Collett B, Ventafridda V, Cohen R, Gallacher D. Survey of chronic pain in Europe: prevalence, impact on daily life, and treatment. Eur J Pain. 2006;10(4):287.

6. Haythornthwaite JA, Hegel MT, Kerns RD. Development of a sleep diary for chronic pain patients. J Pain Symptom Manag. 1991;6(2):65-72.

7. McCracken LM, Iverson GL. Disrupted sleep patterns and daily functioning in patients with chronic pain. Pain Res Manage. 2002;7(2):75-9.

8. Morin CM, Gibson D, Wade J. Self-reported sleep and mood disturbance in chronic pain patients. Clin J Pain. 1998;14(4):311-4.

9. Bastien $\mathrm{CH}$, Vallières $\mathrm{A}$, Morin $\mathrm{CM}$. Validation of the insomnia severity index as an outcome measure for insomnia research. Sleep Med. 2001;2(4):297-307.

10. Tang NKY, Wright KJ, Salkovskis PM. Prevalence and correlates of clinical insomnia co-occurring with chronic back pain. J Sleep Res. 2007;16(1):85-95

11. Atkinson J, Ancoli-Israel S, Slater MA, Garfin SR, Gillin C. Subjective sleep disturbance in chronic back pain. Clin J Pain. 1988;4(4):225-32.

12. Moldofsky H, Scarisbrick P. Induction of neurasthenic musculoskeletal pain syndrome by selective sleep stage deprivation. Psychosom Med. 1976;38(1):35-44.

13. Wolfe F, Michaud K, Li T. Sleep disturbance in patients with rheumatoid arthritis: evaluation by medical outcomes study and visual analog sleep scales. J Rheumatol. 2006:33(10):1942-51.

14. Cappuccio FP, D'Elia L, Strazzullo P, Miller MA. Sleep duration and allcause mortality: a systematic review and meta-analysis of prospective studies. Sleep. 2010;33(5):585-92.

15. Cappuccio FP, D'Elia L, Strazzullo P, Miller MA. Quantity and quality of sleep and incidence of type 2 diabetes: a systematic review and metaanalysis. Diabetes Care. 2010;33(2):414-20.

16. Cappuccio FP, Taggart FM, Kandala N-B, Currie A, Peile E, Stranges S, et al. Meta-analysis of short sleep duration and obesity in children and adults. Sleep. 2008;31(5):619-26.

17. Haack M, Mullington JM. Sustained sleep restriction reduces emotional and physical well-being. Pain. 2005;119(1-3):56-64.

18. Smith MT, Edwards RR, McCann UD, Haythornthwaite JA. The effects of sleep deprivation on pain inhibition and spontaneous pain in women. Sleep. 2007;30(4):494-505.

19. Kundermann B, Krieg J-C, Schreiber W, Lautenbacher S. The effects of sleep deprivation on pain. Pain Res Manage. 2004;9(1):25-32.

20. Lentz MJ, Landis CA, Rothermel J, Shaver JL. Effects of selective slow wave sleep disruption on musculoskeletal pain and fatigue in middle aged women. J Rheumatol. 1999;26(7):1586-92.

21. Tang NKY, Goodchild CE, Sanborn AN, Howard J, Salkovskis PM. Deciphering the temporal link between pain and sleep in a heterogeneous chronic pain patient sample: a multilevel daily process study. Sleep. 2012;35(5):675-87.

22. Wiklund T, Gerdle B, Linton SJ, Dragioti E, Larsson B. Insomnia is a risk factor for spreading of chronic pain: a Swedish longitudinal population study (SwePain). Eur J Pain. 2020;24(7):1348-56.

23. Skarpsno ES, Mork PJ, Nilsen TIL, Nordstoga AL. Influence of sleep problems and co-occurring musculoskeletal pain on long-term prognosis of chronic low back pain: the HUNT study. J Epidemiol Community Health. 2020;74(3):283-9.

24. Haack M, Simpson N, Sethna N, Kaur S, Mullington J. Sleep deficiency and chronic pain: potential underlying mechanisms and clinical implications. Neuropsychopharmacology. 2020;45(1):205-16.

25. Koffel E, Kats AM, Kroenke K, Bair MJ, Gravely A, DeRonne B, et al. Sleep disturbance predicts less improvement in pain outcomes: secondary analysis of the SPACE randomized clinical trial. Pain Med. 2020;21(6):1162-7.

26. Casarett D, Karlawish J, Sankar P, Hirschman K, Asch DA. Designing pain research from the patient's perspective: what trial end points are important to patients with chronic pain? Pain Med. 2001;2(4):309-16.
27. Turk DC, Dworkin RH, Revicki D, Harding G, Burke LB, Cella D, et al. Identifying important outcome domains for chronic pain clinical trials: an IMMPACT survey of people with pain. PAIN ${ }^{\circledR}$. 2008;137(2):276-85

28. Theadom A, Cropley M. 'This constant being woken up is the worst thing'-experiences of sleep in fibromyalgia syndrome. Disabil Rehabil. 2010;32(23):1939-47.

29. Tang NKY, Lereya ST, Boulton H, Miller MA, Wolke D, Cappuccio FP. Nonpharmacological treatments of insomnia for long-term painful conditions: a systematic review and meta-analysis of patient-reported outcomes in randomized controlled trials. Sleep. 2015;38(11):1751-64.

30. Selvanathan J, Pham C, Nagappa M, Peng PW, Englesakis M, Espie CA, et al. Cognitive behavioral therapy for insomnia in patients with chronic pain-a systematic review and Meta-analysis of randomized controlled trials. Sleep Med Rev. 2021;60:101460.

31. Krystal AD. A compendium of placebo-controlled trials of the risks/benefits of pharmacological treatments for insomnia: the empirical basis for US clinical practice. Sleep Med Rev. 2009;13(4):265-74.

32. Modén B, Merlo J, Ohlsson H, Rosvall M. Psychotropic drugs and falling accidents among the elderly: a nested case control study in the whole population of Scania, Sweden. J Epidemiol Community Health. 2010;64(5):440-6.

33. Kramer M. Hypnotic medication in the treatment of chronic insomnia: non nocere! Doesn't anyone care? Sleep Med Rev. 2000;4(6):529-41.

34. Kapustin D, Bhatia A, McParland A, Trivedi A, Davidson A, Brull R, et al. Evaluating the impact of gabapentinoids on sleep health in patients with chronic neuropathic pain: a systematic review and meta-analysis. Pain. 2020;161(3):476-90.

35. Tang NKY, Stella MT, Banks PD, Sandhu HK, Berna C. The effect of opioid therapy on sleep quality in patients with chronic non-malignant pain: a systematic review and exploratory meta-analysis. Sleep Med Rev. 2019:45:105-26.

36. Glass J, Lanctôt KL, Herrmann N, Sproule BA, Busto UE. Sedative hypnotics in older people with insomnia: meta-analysis of risks and benefits. Bmj. 2005;331(7526):1169.

37. Kripke DF, Langer RD, Kline LE. Hypnotics' association with mortality or cancer: a matched cohort study. BMJ Open. 2012;2(1):e000850.

38. de Gage SB, Bégaud B, Bazin F, Verdoux H, Dartigues J-F, Pérès K, et al. Benzodiazepine use and risk of dementia: prospective population based study. Bmj. 2012;345:e6231.

39. Stewart R, Besset A, Bebbington P, Brugha T, Lindesay J, Jenkins R, et al. Insomnia comorbidity and impact and hypnotic use by age group in a national survey population aged 16 to 74 years. Sleep. 2006;29(11):1391-7.

40. NICE. Hypnotics Key Therapeutic Topic KTT6 [Available from: https:// www.nice.org.uk/advice/ktt6.

41. Jones JD, Mogali S, Comer SD. Polydrug abuse: a review of opioid and benzodiazepine combination use. Drug Alcohol Depend. 2012;125(1-2):8-18.

42. Sweetman A, Putland S, Lack L, McEvoy RD, Adams R, Grunstein R, et al. The effect of cognitive behavioural therapy for insomnia on sedativehypnotic use: a narrative review. Sleep Med Rev. 2021;56:101404.

43. Schutte-Rodin S, Broch L, Buysse D, Dorsey C, Sateia M. Clinical guideline for the evaluation and management of chronic insomnia in adults. J Clin Sleep Med. 2008;4(5):487-504.

44. Wilson S, Anderson K, Baldwin D, Dijk D-J, Espie A, Espie C, et al. British Association for Psychopharmacology consensus statement on evidence-based treatment of insomnia, parasomnias and circadian rhythm disorders: an update. J Psychopharmacol. 2019;33(8):0269881119855343.

45. Sateia MJ, Buysse DJ, Krystal AD, Neubauer DN, Heald JL. Clinical practice guideline for the pharmacologic treatment of chronic insomnia in adults: an American Academy of sleep medicine clinical practice guideline. J Clin Sleep Med. 2017;13(2):307-49.

46. Riemann D, Baglioni C, Bassetti C, Bjorvatn B, Dolenc Groselj L, Ellis JG, et al. European guideline for the diagnosis and treatment of insomnia. J Sleep Res. 2017;26(6):675-700.

47. Prados G, Miró E, Martínez MP, Sánchez Al, Lami MJ, Cáliz R. Combined cognitive-behavioral therapy for fibromyalgia: effects on polysomnographic parameters and perceived sleep quality. Int J Clin Health Psychol. 2020;20(3):232-42.

48. Perlis ML, Smith MT. How can we make CBT-I and other BSM services widely available? J Clin Sleep Med. 2008;4(01):11-3. 
49. Barsevick A, Beck SL, Dudley WN, Wong B, Berger AM, Whitmer $\mathrm{K}$, et al. Efficacy of an intervention for fatigue and sleep disturbance during cancer chemotherapy. J Pain Symptom Manag. 2010;40(2):200-16.

50. Mack LJ, Rybarczyk BD. Behavioral treatment of insomnia: a proposal for a stepped-care approach to promote public health. Nat Sci Sleep. 2011;3:87.

51. McCrae CS, Williams J, Roditi D, Anderson R, Mundt JM, Miller MB, et al. Cognitive behavioral treatments for insomnia and pain in adults with comorbid chronic insomnia and fibromyalgia: clinical outcomes from the SPIN randomized controlled trial. Sleep. 2019;42(3):zsy234.

52. Pigeon WR, Moynihan J, Matteson-Rusby S, Jungquist CR, Xia Y, Tu X, et al. Comparative effectiveness of CBT interventions for co-morbid chronic pain \& insomnia: a pilot study. Behav Res Ther. 2012;50(11):685-9.

53. Vitiello MV, McCurry SM, Shortreed SM, Balderson BH, Baker LD, Keefe $\mathrm{FJ}$, et al. Cognitive-behavioral treatment for comorbid insomnia and osteoarthritis pain in primary care: the lifestyles randomized controlled trial. J Am Geriatr Soc. 2013;61(6):947-56.

54. Vitiello MV, Rybarczyk B, Von Korff M, Stepanski EJ. Cognitive behavioral therapy for insomnia improves sleep and decreases pain in older adults with co-morbid insomnia and osteoarthritis. J Clin Sleep Med. 2009;5(4):355-62.

55. Lami MJ, Martínez MP, Miro E, Sanchez Al, Prados G, Caliz R, et al. Efficacy of combined cognitive-behavioral therapy for insomnia and pain in patients with fibromyalgia: a randomized controlled trial. Cogn Ther Res. 2018:42(1):63-79.

56. Tang NKY, Moore C, Parsons H, Sandhu HK, Patel S, Ellard DR, et al. Implementing a hybrid cognitive-behavioural therapy for pain-related insomnia in primary care: lessons learnt from a mixed-methods feasibility study. BMJ Open. 2020;10(3):e034764.

57. Tang NKY, Goodchild CE, Salkovskis PM. Hybrid cognitive-behaviour therapy for individuals with insomnia and chronic pain: a pilot randomised controlled trial. Behav Res Ther. 2012;50(12):814-21.

58. Braun V, Clarke V. Using thematic analysis in psychology. Qual Res Psychol. 2006;3(2):77-101.

59. Public, Health, England. National General Practice Profiles 2019 [Available from: https://fingertips.phe.org.uk/profile/general-practice.

60. Statistics, National, Office. English Indices of Deprivation - 2019. 2019 [Available from: https://www.gov.uk/government/statistics/englishindices-of-deprivation-2019.

61. Klaber Moffett J, Underwood M, Gardiner E. Socioeconomic status predicts functional disability in patients participating in a back pain trial. Disabil Rehabil. 2009;31(10):783-90.

62. Grandner MA, Patel NP, Gehrman PR, Xie D, Sha D, Weaver T, et al. Who gets the best sleep? Ethnic and socioeconomic factors related to sleep complaints. Sleep Med. 2010;11(5):470-8.

63. Nowell LS, Norris JM, White DE, Moules NJ. Thematic analysis: striving to meet the trustworthiness criteria. Int J Qual Methods. 2017;16(1):1609406917733847.

64. Braun V, Clarke V. What can "thematic analysis" offer health and wellbeing researchers? Int J Qual Stud Health Well Being. 2014;9:26152

65. Morgan K. Psychological and pharmacological treatments for insomnia: blending for patient benefit. Sleep Med Rev. 2021;56:101415

66. Koffel E, Kroenke K, Bair MJ, Leverty D, Polusny MA, Krebs EE. The bidirectional relationship between sleep complaints and pain: analysis of data from a randomized trial. Health Psychol. 2016;35(1):41.

67. Andersen ML, Araujo P, Frange C, Tufik S. Sleep disturbance and pain: a tale of two common problems. Chest. 2018;154(5):1249-59.

68. Finan PH, Goodin BR, Smith MT. The association of sleep and pain: an update and a path forward. J Pain. 2013;14(12):1539-52.

69. Fiedler M, Coryell A, Hulla R, Gatchel R. Sleep and pain: a biopsychosocial perspective. EC Anaesthesia. 2018;4:362-71.

70. Tang NKY. Cognitive-behavioral therapy for sleep abnormalities of chronic pain patients. Curr Rheumatol Rep. 2009;11(6):451.

71. Montgomery P, Dennis J. A systematic review of non-pharmacological therapies for sleep problems in later life. Sleep Med Rev. 2004;8(1):47-62.

72. Scholz S, Ngoli B, Flessa S. Rapid assessment of infrastructure of primary health care facilities-a relevant instrument for health care systems management. BMC Health Serv Res. 2015;15(1):183.
73. Luxon L. Infrastructure-the key to healthcare improvement. Future Hosp J. 2015;2(1):4.

74. Parsons S, Harding G, Breen A, Foster N, Pincus T, Vogel S, et al. The influence of patients' and primary care practitioners' beliefs and expectations about chronic musculoskeletal pain on the process of care: a systematic review of qualitative studies. Clin J Pain. 2007;23(1):91-8.

75. Mills S, Torrance N, Smith BH. Identification and management of chronic pain in primary care: a review. Curr Psychiatry Rep. 2016;18(2):22.

76. Slade SC, Kent P, Patel S, Bucknall T, Buchbinder R. Barriers to primary care clinician adherence to clinical guidelines for the management of low back pain. Clin J Pain. 2016;32(9):800-16.

77. Sartorius N. Comorbidity of mental and physical disorders: a main challenge to medicine in the 21st century. Psychiatr Danub. 2013;25(Suppl 1):4-5.

78. Jacobsen PB, Prasad R, Villani J, Lee C-M, Rochlin D, Scheuter C, et al. The role of economic analyses in promoting adoption of behavioral and psychosocial interventions in clinical settings. Health Psychol. 2019;38(8):680.

79. Lichstein KL. Secondary insomnia: a myth dismissed. Sleep Med Rev. 2006;10(1):3-5.

80. Briggs EV, Battelli D, Gordon D, Kopf A, Ribeiro S, Puig MM, et al. Current pain education within undergraduate medical studies across Europe: advancing the provision of pain education and learning (APPEAL) study. BMJ Open. 2015;5(8):e006984.

81. Carr EC, Briggs EV, Briggs M, Allcock N, Black P, Jones D. Understanding factors that facilitate the inclusion of pain education in undergraduate curricula: perspectives from a UK survey. Br J Pain. 2016;10(2):100-7.

82. Landis CA, Lentz MJ, Rothermel J, Buchwald D, Shaver JL. Decreased sleep spindles and spindle activity in midlife women with fibromyalgia and pain. Sleep. 2004;27(4):741-50.

83. Onen SH, Alloui A, Gross A, Eschallier A, Dubray C. The effects of total sleep deprivation, selective sleep interruption and sleep recovery on pain tolerance thresholds in healthy subjects. J Sleep Res. 2001;10(1):35-42.

84. Koffel E, Amundson E, Wisdom JP. Exploring the Meaning of Cognitive Behavioral Therapy for Insomnia for Patients with Chronic Pain. Pain Med. 2020;21(1):67-75.

85. Almoznino G, Haviv Y, Sharav Y, Benoliel R. An update of management of insomnia in patients with chronic orofacial pain. Oral Dis. 2017;23(8):1043-51.

86. Espie CA, MacMahon KM, Kelly H-L, Broomfield NM, Douglas NJ, Engleman HM, et al. Randomized clinical effectiveness trial of nurse-administered small-group cognitive behavior therapy for persistent insomnia in general practice. Sleep. 2007;30(5):574-84.

87. Barlow J, Sturt J, Hearnshaw H. Self-management interventions for people with chronic conditions in primary care: examples from arthritis, asthma and diabetes. Health Educ J. 2002;61 (4):365-78.

88. Stannard C, Johnson M. Chronic pain management-can we do better? An interview-based survey in primary care. Curr Med Res Opin. 2003;19(8):703-6.

89. Cheatle MD, Foster S, Pinkett A, Lesneski M, Qu D, Dhingra L. Assessing and managing sleep disturbance in patients with chronic pain. Anesthesiol Clin. 2016;34(2):379-93.

90. Price C, Hoggart B, Olukoga O, de Williams A, Bottle A. National Pain Audit 2010-2012. London: The British Pain Society.

91. McGhie J, Grady K. Where now for UK chronic pain management services? Br Jr Anaesthesia. 2016;116(2):159-62.

92. Fernández A, Saameno JAB, Pinto-Meza A, Luciano JV, Autonell J, Palao $D$, et al. Burden of chronic physical conditions and mental disorders in primary care. Br J Psychiatry. 2010;196(4):302-9.

93. Hobbs FR, Bankhead C, Mukhtar T, Stevens S, Perera-Salazar R Holt T, et al. Clinical workload in UK primary care: a retrospective analysis of 100 million consultations in England, 2007-14. Lancet. 2016;387(10035):2323-30

94. Hadi MA, Alldred DP, Briggs M, Marczewski K, Closs SJ. 'Treated as a number, not treated as a person': a qualitative exploration of the perceived barriers to effective pain management of patients with chronic pain. BMJ Open. 2017;7(6):e016454. 
95. Excellence Nifhac. Guideline Scope. Chronic pain: assessment and management 2018.

96. Brown BB, Patel C, Mclnnes E, Mays N, Young J, Haines M. The effectiveness of clinical networks in improving quality of care and patient outcomes: a systematic review of quantitative and qualitative studies. BMC Health Serv Res. 2016;16(1):360.

97. Luik Al, Kyle SD, Espie CA. Digital cognitive behavioral therapy (dCBT) for insomnia: a state-of-the-science review. Curr Sleep Med Rep. 2017:3(2):48-56

98. Morin CM. Profile of Somryst prescription digital therapeutic for chronic insomnia: overview of safety and efficacy. Expert Rev Med Devices. 2020;17(12):1239-48.

99. Elison S, Ward J, Williams C, Espie C, Davies G, Dugdale S, et al. Feasibility of a UK community-based, eTherapy mental health service in Greater Manchester: repeated-measures and between-groups study of'Living Life to the Full Interactive,'Sleepio'and 'Breaking Free Online'at 'Self Help Services'. BMJ Open. 2017;7(7):e016392.

100. Freeman D, Sheaves B, Goodwin GM, Yu L-M, Nickless A, Harrison PJ, et al. The effects of improving sleep on mental health (OASIS): a randomised controlled trial with mediation analysis. Lancet Psychiatry. 2017;4(10):749-58.

101. Espie CA, Emsley R, Kyle SD, Gordon C, Drake CL, Siriwardena AN, et al. Effect of digital cognitive behavioral therapy for insomnia on health, psychological well-being, and sleep-related quality of life: a randomized clinical trial. JAMA Psychiatry. 2019;76(1):21-30.

102. Luik Al, Bostock S, Chisnall L, Kyle SD, Lidbetter N, Baldwin N, et al. Treating depression and anxiety with digital cognitive behavioural therapy for insomnia: a real world NHS evaluation using standardized outcome measures. Behav Cogn Psychother. 2017;45(1):91-6.

103. Pinheiro MB, Ho KK, Ferreira ML, Refshauge KM, Grunstein R, Hopper JL, et al. Efficacy of a sleep quality intervention in people with low back pain: protocol for a feasibility randomized co-twin controlled trial. Twin Res Hum Genet. 2016;19(5):492-501.

104. Malterud K, Siersma VD, Guassora AD. Sample size in qualitative interview studies: guided by information power. Qual Health Res. 2016;26(13):1753-60.

105. Guest G, Bunce A, Johnson L. How many interviews are enough? An experiment with data saturation and variability. Field Methods. 2006;18(1):59-82.

106. Glaser BG, Strauss AL. Discovery of grounded theory: strategies for qualitative research: Routledge; 2017.

\section{Publisher's Note}

Springer Nature remains neutral with regard to jurisdictional claims in published maps and institutional affiliations.
Ready to submit your research? Choose BMC and benefit from:

- fast, convenient online submission

- thorough peer review by experienced researchers in your field

- rapid publication on acceptance

- support for research data, including large and complex data types

- gold Open Access which fosters wider collaboration and increased citations

- maximum visibility for your research: over $100 \mathrm{M}$ website views per year

At BMC, research is always in progress.

Learn more biomedcentral.com/submissions 